\title{
Terapias alternativas na endodontia- ozonioterapia: Revisão de literatura
}

\author{
Alternative therapies in endodontics- ozoniotherapy: Literature review \\ Terapias alternativas en endodoncia- ozonioterapia: Revisión de la literatura
}

Recebido: 03/05/2021 | Revisado: 10/05/2021 | Aceito: 15/05/2021 | Publicado: 31/05/2021

\author{
Larissa Deusdará Paixão \\ ORCID: https://orcid.org/0000-0002-8273-8097 \\ Faculdade Patos de Minas, Brasil \\ E-mail: larissa.13036@alunofpm.com.br \\ Lia Dietrich \\ ORCID: https://orcid.org/0000-0001-7887-8591 \\ Clínica Privada, Brasil \\ E-mail: lia_dietrich@yahoo.com.br \\ Leopoldo Henrique Barboza Martins \\ ORCID: https://orcid.org/0000-0001-6739-8509 \\ Faculdade Patos de Minas, Brasil \\ E-mail: leopoldo.martins@faculdadepatosdeminas.edu.br \\ Dalila Viviane de Barros \\ ORCID: https://orcid.org/0000-0002-3988-0629 \\ Faculdade Patos de Minas, Brasil \\ E-mail dalila.barros@faculdadepatosdeminas.edu.br
}

\begin{abstract}
Resumo
A Ozonioterapia como coadjuvante no tratamento endodôntico tem ganhado grande espaço, devido suas propriedades terapêuticas como, ação antimicrobianas, regeneração tecidual e potencial cicatrizante, sendo um dos fatores para o sucesso da endodontia. Dessa forma, a Ozonioterapia apresenta diversas formas de aplicação com potencial de descontaminação, através de gás, águas e óleos ozonizados, podendo ser utilizados em conjunto ou separadamente. Dentre esse contexto, o objetivo deste trabalho é informar sobre os benefícios e malefícios da utilização do ozônio como uma forma terapêutica na endodontia, além de esclarecer sobre como surgiu e suas formas de ação de acordo com a forma que seja utilizada. A metodologia empregada constituiu em realizar uma revisão narrativa da literatura pesquisada em bases de dados cientificos, como: Scielo, Bvsalud, Redalyc e Sciencedirect. Assim, a Ozonioterapia atua como uma terapia alternativa no tratamento endodôntico, podendo ser utilizado tanto em medicações intracanais como um agente irrigante, capaz de agir sobre bactérias, fungos, protozoários e vírus dentro do sistema de canais radiculares. Conclui-se que a Ozonioterapia como auxiliar no tratamento endodôntico é de grande valia, mas que é necessário o desenvolvimento de técnicas que padronize as formas e tempo de aplicação do ozônio.
\end{abstract}

Palavras-chave: Ozônio; Endodontia; Terapias complementares; Odontologia.

\begin{abstract}
Ozone therapy as an adjuvant in endodontic treatment has gained great space, due to its therapeutic properties such as antimicrobial action, tissue regeneration and healing potential, being one of the factors for the success of endodontics. Thus, Ozonoterapia presents several forms of application with potential for decontamination, through gas, water and ozonized oils, which can be used together or separately. Within this context, the objective of this work is to inform about the benefits and harms of the use of ozone as a therapeutic form in endodontics, in addition to clarifying how it emerged and its forms of action according to the form that it is used. The methodology used consisted of carrying out a narrative review of the literature, researched in scientific databases, such as: Scielo, Bvsalud, Redalyc and Sciencedirect. Thus, Ozonotherapy acts as an alternative therapy in endodontic treatment, being able to be used both in intracanal medications as an irrigating agent, able to act on bacteria, fungi, protozoa and viruses within the root canal system. It is concluded that ozone therapy as an aid in endodontic treatment is of great value, but that it is necessary to develop techniques that standardize the forms and time of ozone application.
\end{abstract}

Keywords: Ozone; Endodontics; Complementary therapies; Dentistry.

\section{Resumen}

La Ozonoterapia como coadyuvante en el tratamiento endodóntico ha ganado un gran espacio, debido a sus propiedades terapéuticas como la acción antimicrobiana, la regeneración tisular y el potencial cicatrizante, siendo uno de los factores del éxito de la endodoncia. Así, la Ozonoterapia presenta varias formas de aplicación con potencial de descontaminación, a través de gas, agua y aceites ozonizados, que pueden usarse juntos o por separado. En este contexto, el objetivo de este trabajo es informar sobre los beneficios y perjuicios del uso del ozono como forma terapéutica en endodoncia, además de aclarar cómo surgió y sus formas de acción según la forma en que se utilice. La 
metodología utilizada consistió en realizar una revisión narrativa de la literatura, investigada en bases de datos científico, tales como: Scielo, Bvsalud, Redalyc y Sciencedirect. Así, la Ozonoterapia actúa como una terapia alternativa en el tratamiento de endodoncia, pudiendo ser utilizada tanto en medicamentos intracanal como agente irrigante, pudiendo actuar sobre bacterias, hongos, protozoos y virus dentro del sistema de conductos radiculares. Se concluye que la ozonoterapia como coadyuvante en el tratamiento endodóntico es de gran valor, pero que es necesario desarrollar técnicas que estandaricen las formas y tiempos de aplicación del ozono.

Palabras clave: Ozono; Endodoncia; Terapias complementarias; Odontología.

\section{Introdução}

As buscas por novas substâncias que auxiliam na terapêutica são constantes e que não causem danos aos tecidos, dessa forma a Ozonioterapia é utilizada pela Odontologia e Medicina de forma auxiliar no tratamento de várias doenças crônicas e agudas (França,2019; Ferreira, 2011; Martin, 2018; Nesi, 2018). Sendo aceita em 1880 nos Estados Unidos a Ozonioterapia tem sido utilizada a mais de 130 anos por cerca de 20 países do mundo incluindo o Brasil (França,2019). Sua regulamentação através do Conselho Federal de Odontologia foi realizada em 2015, por meio da Resolução de número 166, definindo a terapia com ozônio como apenas um procedimento experimental para a prática médica, bastante promissora entre os pesquisadores e clínicos (França, 2019; Silva, 2019; Martin, 2018; Nimer, 2018).

Assim o Ozônio pode ser definido como um composto alotrópico do oxigênio, formado por descargas elétricas diante a molécula de oxigênio que se quebra e libera os átomos que se ligaram e formaram o O3 também chamado de Ozônio (Martin, 2018; Nesi, 2018). Sendo bastante instável e oxidante o ozônio retoma sua forma de oxigênio facilmente, visto pela Medicina como um potencializador da cicatrização e reparação de tecidos (Nesi, 2018). As propriedades terapêuticas do Ozônio na Odontologia são diversas, porém a mais evidente é o seu potencial antimicrobiano, além de possuir ativação da oxigenação dos tecidos que auxiliará na regeneração tecidual e nas propriedades cicatrizantes (Ferreira, Mariano, Gárcia Junior, \& Pellizer, 2013; Martin, 2018).

Historicamente, o primeiro relato de utilização da Ozonioterapia no âmbito odontológico se deu em 1950 em tratamentos de periodontites com a água ozonizada (Ferreira, 2011). A Ozonioterapia possui grande abrangência na Odontologia sendo no tratamento de cárie, na prevenção e tratamento de quadros inflamatórios/infecciosos, infecções agudas e crônicas, sanitização de canais radiculares, reparação tecidual, dor, disfunção temporomandibular, osteomielite, osteoradionecrose e necroses induzidas por medicamentos (Nesi, 2018). Dessa forma, o ozônio utilizado na endodontia se baseia nos estudos de Zbiden e Overdiek e Honrath, na qual vem gerando novas aplicações e protocolos no tratamento radicular, de forma que se foi notado à complexidade das infecções endodônticas de acordo com a anatomia (Moreira, Reis, Dietrich, Martins, \& Barros, 2019).

Apesar de tudo, o efeito antimicrobiano do ozônio na Odontologia é pouco divulgado, porém vários estudos estão sendo desenvolvidos, pois seu gás tem demonstrado grande eficácia contra diversas espécies microbianas da cavidade oral (Farac, 2010). As formas de utilização da Ozonioterapia são grandes, sendo seu mecanismo de ação relacionado a procedimentos minimamente invasivos e efetivos, além de ser biológico e sem sintomatologia (Nogales \& Franscinp, 2014). Para que se possa fazer a utilização dessa terapia é necessária uma habilitação, além da conclusão de curso da formação especifica com certificação pela instituição de ensino superior que seja registrada pelo Ministério da Educação, é necessário que tenha no seu conteúdo programático a habilitação em Ozonioterapia direcionada a Odontologia (Martins, 2018).

Sendo assim, o objetivo deste artigo é levar ao leitor a compreensão da utilização do ozônio como uma terapia alternativa de grande validade na endodontia e em várias áreas odontológica. De forma mais específica, visa os benefícios e malefícios da utilização do ozônio como uma forma terapêutica na Odontologia, além de explicar como surgiu e sua forma de ação quando utilizado de acordo com cada forma seja em gás, água ou óleos nos tratamentos odontológicos. 


\section{Metodologia}

Este artigo é uma revisão de literatura narrativa, com caráter qualitativo, sendo baseadas em análises de artigos científicos, dissertações, teses, TCCs e monografias. Foi utilizado a base bibliográfica da base de dados científicos na internet, Pubmed, Scielo, Bvsalud, Redalyc e Sciencedirect. A pesquisa se deu através da busca por palavras chaves como: Ozônio; Endodontia; Terapias complementares; Odontologia. Os materiais utilizados se enquadrando no período de 2006 à 2019.

\section{Revisão de Literatura}

\subsection{Ozonioterapia na Odontologia}

O Ozônio é um composto molecular natural que possui três átomos de oxigênio, é um composto muito reativo, incolor, parcialmente solúvel em água, odor forte, penetrante e desagradável, foi descoberto em 1840 pelo pesquisador Christian Friedrich Schonbein (França \& Ferreira, 2019; Martins, 2018; Morette, 2011; Oliveira et al, 2018; Santos, 2018). A Ozonioterapia vem sendo bastante utilizada na Odontologia e na Medicina, na qual se baseia na utilização do ozônio medicinal para tratamento terapêutico alternativo de diversas doenças, tendo atuação na eliminação do foco da doença induzindo uma resposta natural para cura do organismo (Moreira et al, 2019; Nesi, 2018; Nimer, 2018; Paez, Pereira, Assis, Santos, \& Tim, 2020).

$\mathrm{Na}$ prática odontológica, o Ozônio tem sido uma terapia alternativa diferenciada por possuir atividades como antimicrobiana, analgésica, anti-inflamatória, fungicida, viricida, regeneração tecidual, hemostáticas, ativação da oxigenação dos tecidos, ações cicatrizantes e ação antioxidante (Belegote et al, 2018; Cruz, 2006; Farac, 2010; França \& Ferreira, 2019; Martins, 2018; Nimer, 2018; Nogales \& Franscinp, 2014; Nogales et al, 2016; Paez et al, 2020; Santos, 2018; Silva \& Drummond 2019; Saraiva et al, 2019). Por possuir um baixo custo e aplicação minimamente invasiva, a Ozonioterapia possui vários benefícios, trazendo para a Odontologia várias utilizações em diferentes situações clínicas (Belegote et al, 2018; Paez et al, 2020). Os efeitos que o Ozônio realiza podem ser utilizados em vários campos da Odontologia, sendo na periodontia, implantodontia, cirurgia bucomaxilofacial, endodontia, cariologia, dentística, hipersensibilidade, estomatologia, higienização de próteses e de instrumentos, entre outro, todos aprovados pelo Conselho Federal de Odontologia (Nimer, 2018; Oliveira et al, 2018).

Quando utilizado na Odontologia o gás oxigênio é produzido por geradores elétricos, que forma Ozônio pela passagem do oxigênio puro por um campo elétrico, ele se dissocia e os átomos instáveis de oxigeno se ligam e formam outro átomo sendo denominado de Ozônio (Martins, 2018). Devido a sua alta instabilidade o Ozônio produzido pode ser utilizado de forma terapêutica em diferentes concentrações, como na forma de ozônio gasoso, água ozonizada e óleo ozonizado, quando associado ao óleo deve ser utilizados óleos vegetais como o de girassol e o de oliva que permitem o seu armazenamento alguns meses se mantido sob refrigeração (Martins, 2018; Nimer, 2018; Rolin, 2018; Silva, 2019). Em associação com o óleo vegetal o Ozônio apresenta características como, antimicrobianas, efeito debridante, estimula a angiogênese e antioxidante, porém o Ozônio está sendo muito associado à água e utilizado topicamente possuindo características biológicas como antimicrobiano efeito debridante, estimula a angiogênese e antioxidante, já na forma de gás possui eficiência de redução de dores, redução de hipersensibilidades de forma mais prolongada e ação anti-inflamatória (Cruz, 2006; Nimer, 2018; Nogales \& Franscinp, 2014; Silva \& Drummond, 2019).

O Ozônio administrado em condições terapêuticas e de forma controlada o organismo reconhece o gás como um complemento que o auxiliará na ativação de anticorpos para produção da resposta imunológica contra os patógenos (Nogales et al, 2016). Em baixas concentrações ele produz efeitos de hipocoagulação moderada, assim todas as medicações utilizadas para redução da coagulação sanguínea devem ser suspensas durante a Ozonioterapia (França \& Ferreira, 2019). Já em aplicações locais ele pode apresentar propriedades antimicrobianas, anti-inflamatórias, analgésicas e reparação tecidual, atuando como um 
mediador neuroquímico da sensação dolorosa, facilitando assim a eliminação e a metabolização dos mediadores inflamatórios (Ferreira et al, 2013; Silva, 2019).

Como mencionado anteriormente, o ozônio possui uma forte característica antibacteriana, possuindo capacidade de destruir todas as bactérias Gram-positivas e Gram-negativas, sendo as Gram-positivas mais sensíveis que as negativas (Ferreira et al, 2013; Santos, 2018; Silva \& Drummond, 2019). O Ozônio possui propriedade comprovada na destruição de bactérias como Streptococcus mutans, Streptococcus sanguis, Actinomyces odontolyticus e várias outras encontradas na cavidade oral (Cruz, 2006). Ele irá agir na membrana celular causando a ruptura e a lise devido a sua ação sobre os ácidos graxos poliinsaturados, agindo ainda no aumento do suprimento de oxigênio local, causando hemostasia e inibindo a proliferação bacteriana de várias doenças, dentre elas, câncer, artrite reumatoide e HIV (Nogales et al, 2016; Noites et al, 2014).

Com sua alta capacidade oxidativa, o Ozônio agirá diretamente na membrana celular das bactérias, causando uma permeabilidade alta que altera as funções das bactérias, oxidando assim as enzimas, proteínas, DNA e RNA levando a lise das bactérias, causando resposta dos fibroblastos e epitélio gengival (Farac, 2010; França \& Ferreira, 2019; Silva, 2019; Silva e Drummond, 2019; Rolim, 2018). Devido a sua ação antioxidante, ocorre à produção apenas de oxigênio como um subproduto, que chega aos tecidos incentivando a reparação tecidual, neutralizando a sintomatologia dolorosa, eliminando os mediadores inflamatórios e ativando a resposta imunológica contra agentes patológicos (Silva \& Drummond, 2019). Ele estimulará a proliferação de células imunocompoetentes e síntese de imunoglobulinas, ativando assim a função do macrófago contra a fagocitose (Ajeti, Krasnigi, \& Apostolska, 2018).

Ao reconhecermos a vasta ação da Ozonioterapia, podemos introduzir na Odontologia e utiliza em várias áreas de tratamento, visto que é uma terapia muito promissora e benéfica como coadjuvante associada às terapias convencionais (Silva, 2019; Silva \& Drummond, 2019). Lembrando sempre que, o ozônio é um complemento das técnicas convencionais, pois assim terá resultados positivos e menos invasivos comparados com outras terapias alternativas utilizadas tanto na Odontologia quanto na Medicina (Silva, 2019; Nimer, 2018).

\subsection{Efeito do ozônio como terapia alternativa na endodontia}

A terapia endodôntica tem como objetivo a eliminação e neutralização das toxinas endodônticas, liberadas pelos microrganismos que acometem a polpa e os tecidos perirradiculares que causam alterações patológicas nessas estruturas dentarias (Martins, 2018). Sendo o sucesso do tratamento relacionado à eliminação dos microrganismos dos canais radiculares antes da obturação, o que se torna uma preocupação constante na endodontia, pois nem sempre esse objetivo é alcançado (Ajeti et al, 2018; Nimer, 2018; Noites et al, 2014). Por se ter essas preocupações várias substâncias químicas estão sendo utilizadas para trazer mais eficácia para a técnica endodôntica tradicional, onde o uso da terapia utilizando ozônio vem sendo aceita no tratamento endodôntico através de águas ozonizadas para irrigação, gás e óleos ozonizados para acelerar a cura das infecções (França \& Ferreira, 2019; Martins, 2018; Moreira et al, 2019; Silva, 2019).

Perante isso, o ozônio possui grande capacidade de ser inserido na endodontia, pois ele possui propriedade como ação antimicrobiana, efeito debridante, estimula angiogênese, efeito oxidante, além de ser biocompatível (Ajeti et al, 2018; Ferreira, 2011; Nogales et al, 2016 Silva, 2019;). Quando prescrito em concentração e tempo adequado o efeito antimicrobiano do ozônio irá danificar a membrana citoplasmática, por meio da osmose de dupla ligação e efeito intracelular pela oxidação, trazendo uma redução da flora periapical e estimulando a regeneração óssea apical (Ajeti et al, 2018; França \& Ferreira, 2019; Nesi, 2018). Assim, a Ozonioterapia é uma proposta adicional ao tratamento endodôntico convencional, sendo um auxílio ao processo de descontaminação, podendo ser utilizado potencialmente através do gás de ozônio, água e óleos ozonizados podendo ser usufruído isoladamente ou em conjunto (França \& Ferreira, 2019; Martins, 2018; Nesi, 2018; Nogales et al, 2016).

$\mathrm{Na}$ endodontia, o ozônio pode ser utilizado como medicação intracanal e como agente irrigante agindo sobre vários 
microrganismos como, bactérias, fungos, protozoários e vírus presente nos canais radiculares (Farac, 2010; Oliveira et al, 2018). A água ozonizada como agente irrigante complementar mostrou ser capaz de minimizar a presença de Enterococcus faecalis, Streptococcus mutans, Peptostreptococcus micros, Pseudômonas aeruginosa e Cândida albicans (Ferreira, 2011; Martins, 2018; Nogales \& Franscinp, 2014; Oliveira et al, 2018). Porém, a água ozonizada mostra-se mais eficaz como agente irrigante quando associada com a agitação do ultrassom, reduzindo drasticamente a quantidade de bactérias presentes nos canais radiculares, mas não é tão eficiente para neutralizar as toxinas endodônticas (Martins, 2018; Nesi, 2018; Nogales \& Franscinp, 2014; Silva, 2019).

Os óleos ozonizados possuem capacidade antisséptica contra bactérias comumente encontradas em canais radiculares, podendo ser utilizado como medicação intracanal (Nogales \& Franscinp, 2014; Silva, 2019). Ele pode ser usado como um meio para esterilizar os sistemas de canais radiculares, limpeza de detritos necróticos, isso devido a sua capacidade bactericida e efervescente, sendo em alguns casos mais eficaz que o hipoclorito de sódio e peróxido de sódio juntos na irrigação tradicional (França \& Ferreira, 2019). Para ter uma eficácia maior o óleo ozonizado deve ser misturado com veículos viscosos, isso para que se possa ter uma difusão maior, fazendo com que sua liberação seja gradual e permita uma moderada degradação, sendo mais fácil de remover do canal radicular quando necessário (Cruz, 2006; Nogales \& Franscinp, 2014).

Já a forma gasosa do ozônio possui eficácia contra os patógenos endodônticos, sendo em forma de biofilme ou em suspensão, utilizado como método de desinfecção, tanto antes de restaurações ou em endodontias (Martins, 2018; Nimer, 2018). Sua administração na forma de gás é tópica, podendo ser aplicada de duas formas aberta ou por meio de sucção vedada, reduzindo a população bacteriana através da irrigação intracanal (Nimer, 2018; Silva \& Drummond, 2019). Dessa forma, a Ozônioterapia pode ser aplicada localmente, apresentando propriedades como analgesia e anti-inflamatória, modulando o sistema imune do paciente de forma direta ou indireta, que potencializa a resposta do organismo frente ao agente agressor (Nesi, 2018).

Sobre a cicatrização óssea apical com o ozônio, vimos que ocorre a remoção e secreção de matéria orgânica, promovida pela abertura que ocorre nos poros, que irá induzir a formação de tecido de granulação e a neoangiogênese (França \& Ferreira, 2019). Permitindo assim, a perfusão de íons cálcio e fosfato regionais, causando a reparação do tecido ósseo apical, porém só terá êxito se a reparação for observada em casos de lesão periapical (Nogales \& Franscinp, 2014; Silva, 2019). Isso ocorre devido aos radicais livres que são derivados do oxigênio, que influência a resposta inflamatória, causando a desinfecção e limpeza das feridas, fazendo com que o tecido se adapte com o estresse oxidativo (Cruz, 2006; França \& Ferreira, 2019).

Perante isso, estudos comprovam que o ozônio utilizado juntamente coma técnica convencional torna a terapia assintomática, levando a um reparo favorável (Nogales \& Franscinp, 2014). A Ozonioterapia apresenta uma ação antimicrobiana semelhante ao hipoclorito de sódio em concentração de 2,5\%, não trazendo danos aos tecidos, principalmente na forma de água ozonizada e agitado com ultrassom (Moreira et al, 2019; Nimer, 2018; Nogales, 2011). Como medicação intracanal complementar a melhor forma do ozônio são os óleos, devido seu grande potencial antibacteriano, sendo associado o óleo de girassol ozonizado mais hidróxido de cálcio com paramonoclorofenol e glicerina para doenças periapicais (Cruz, 2006; Nimer, 2018).

Mediante isso, o tratamento da região perirradicular por meio das terapias coadjuvantes como a Ozonioterapia tem como objetivo minimizar significativamente a microbiota instalada nos canais radiculares, juntamente com a técnica convencional endodôntica (França \& Ferreira, 2019; Nogales \& Franscinp, 2014; Silva, 2019). A Ozonioterapia deve ser utilizada como um adjunto ao tratamento endodôntico tradicional, além de ser também um método de prevenção não devendo ser utilizada como uma modalidade de tratamento isolada (França \& Ferreira, 2019; Silva \& Drummond, 2019). Como foi relatado, a terapia com ozônio deve ser coadjuvante na endodontia, seguindo um protocolo rigoroso de trabalho, sendo aplicado pelo tempo adequado e intracanal após os procedimentos tradicionais de limpeza, desinfecção e modelagem dos 
canais radiculares (Ferreira, 2011; Silva, 2019).

\subsection{Ozonioterapia seus benefícios e malefícios}

A Ozonioterapia quando utilizada em doses terapêuticas e de forma tópica possui uma efetividade mais comprovada, visto que seu uso correto reduz bastante a probabilidade de reações adversas (Silva, 2019). Visando as vantagens da utilização do ozônio diluído em água ou na forma gasosa podemos observar o custo-benefício favorável, reduzindo assim a perda de tecido, não causa dor, reduz a ansiedade, fácil aplicação tanto local como sistêmica, ação antimicrobiana, anti-inflamatórias, analgésicas, trazendo um mecanismo eficaz para os Cirurgiões-dentistas (Ferreira, 2011; Silva, 2019).

Apesar dos vastos benefícios da Ozonioterapia citados neste artigo nem todos os pacientes estão aptos a utilizar, sendo contraindicado em casos de gravidez, lactantes, anemia severa, miastenia severa, intoxicação ao álcool aguda, hipertireoidismo, hipoglicemia, cardíacos, quadros de hemorragia e alergias ao ozônio (França \& Ferreira, 2019; Nesi, 2018; Nimer, 2018; Silva, 2019; Silva \& Drummond, 2019). Fatores como concentração, tempo de exposição, capacidade de metabolismo celular do organismo que irá regular a produção dos radicais livres, o que se torna capaz de causar danos às moléculas biológicas, devem ser considerados para que possamos determinar os malefícios causados pelo uso do ozônio (Ferreira, 2011). Por mais que o ozônio seja eficiente e possuir grande benefício, ele é altamente tóxico e age diretamente nos tecidos pulmonares, podendo levar o paciente a óbito, isso se utilizado de forma incorreta, não obedecendo a concentração ideal e o tempo de exposição (Nesi, 2018).

Os principais efeitos colaterais observado na utilização do ozônio são irritação das vias aéreas, rinite, dor de cabeça, tosse, náuseas, vômitos, interrupção da respiração de forma breve, problemas cardíacos, circulação deficiente, inchaço dos vasos sanguíneos, efeitos esses que dependeram do tempo de exposição e da concentração utilizada (França \& Ferreira, 2019; Martins, 2018; Oliveira et al, 2018; Paez et al, 2020; Silva, 2019). Os efeitos adversos que podem ocorrer através da mucosa oral, nasal e ocular podem estar relacionados com queimaduras, tosses, náusea, vômitos e dores de cabeça, no entanto as complicações causadas pela Ozonioterapia são pouco frequentes (França \& Ferreira, 2019; Paez et al, 220).

Também é contraindicado a inalação do ozônio devido o sistema pulmonar ser sensível a oxidação que ele gera podendo ser tóxico para as vias aéreas superiores, podendo causar danos como irritação das vias aéreas superiores, lacrimejamento, rinite, dor de cabeça, náusea e vômito (Martinz, 2018; Morette, 2011; Nogales \& Franscinp, 2014; Silva \& Drummond, 2019). Dessa forma o ozônio é considerado um gás tóxico e irritante quando utilizado na forma de inalação e em altas concentrações traz prejuízo á saúde através de deficiências neurológicas, fadiga, cefaleia e insônia, sendo as formas mais graves da intoxicação por inalação do ozônio (Cruz, 2006; Ferreira, 2011). No caso de intoxicação durante a Ozonioterapia devemos colocar o paciente na posição supina, administrar oxigênio úmido por meio de inalação e administrar medicamentos como ácido ascórbico, vitamina E e N-acetilcisteína (França \& Ferreira, 2019; Nogales \& Franscinp, 2014; Oliveira et al, 2018).

\section{Discussão}

A utilização de tratamentos com o auxílio do ozônio tem sido uma grande inovação nos métodos convencionais desde a Medicina até a Odontologia, visto que vários benefícios vêm sendo demonstrados em alguns estudos (Nimer, 2018). Por ser um agente oxidante o ozônio é capaz de estimular o sistema circulatório e gerar uma resposta imune, sendo utilizado para diversos tratamentos agudos e crônicos, devido sua ação antimicrobiana e biocompatibilidade (Ferreira, 2011; Martins, 2018; Nesi, 2018; Nimer, 2018). Além da sua ação antimicrobiana o ozônio apresenta propriedades analgésicas e anti-inflamatórias em aplicação local, modulando diretamente e indiretamente o sistema imune do paciente (Ferreira et al, 2013; Nesi, 2018; Silva, 2019). O ozônio na Odontologia tem sido utilizado em diversas áreas, na endodontia é utilizado com a pretensão de 
eliminar microrganismos dos canais radiculares antes da obturação, auxiliando a técnica convencional (Nimer, 2018; Silva, 2019).

De acordo com Martins IVR (2018), a Ozonioterapia não deve ser utilizada como substituição das substâncias convencionais, não sendo descartada a utilização de antissépticos já utilizados e sim fazendo um incremento da técnica com o ozônio (Martins, 2018). Morette DA (2011) concorda com Martins IVR (2018) e ainda relata que, o ozônio é utilizado como terapia complementar no tratamento humano, podendo ser utilizado em diversos tratamentos, sendo capaz de levar uma melhor qualidade de vida, aumentando a oxigenação tecidual, reduzindo a carga microbiológica do paciente (Morette, 2011). Já Nesi AK (2018) afirma que, a Ozonioterapia é interessante como auxiliar no tratamento odontológico, pois as bactérias odontológicas são mais sensíveis ao ozônio (Nesi, 2018).

Sobre as formas de utilização do ozônio autores como Nimer HYY (2018), consideram que o óleo ozonizado utilizado de forma intracanal pode ser uma alternativa melhor no tratamento endodôntico, isso devido sua alta atividade antibacteriana contra diversos patógenos endodônticos (Nimer, 2018). Já Cruz HFO (2006) acredita que, com a eficácia da ação antimicrobiana do óleo ozonizado, ele seja capaz de se misturar com veículos viscosos, tendo assim maior poder de difusão e sendo mais fácil a sua remoção do interior do canal (Cruz, 2006). Entretanto Belegote IS et al (2018) acredita que, a irrigação dos canais radiculares com a água ozonizada reduz os sinais clínicos da inflamação e a flora bacteriana, já Nogales CG (2011) defende que a água ozonizada é a que apresenta melhor desempenho antimicrobiano (Bolegote et al, 2018; Nogales, 2011). Silva NLS et al (2019) alegam que, na reparação óssea periapical é eficaz a utilização da água ozonizada como agente irrigante juntamente com o óleo ozonizado como medicação intracanal, sendo capaz de reduzir a sintomatologia e combatendo os microrganismos de forma eficaz (Silva \& Drummond, 2019).

Martins IVR (2018) acredita que, a melhor forma de aplicação do ozônio é após o preparo cirúrgico dos canais, pois dessa forma os detritos são removidos e o ozônio pode penetrar nos túbulos dentinários (Martins, 2018). Martins IVR (2018) ainda defende que a irrigação dos canais com a utilização do ultrassom é mais eficaz do que as técnicas convencionais, alegando que a agitação causada pelo ultrassom possibilita maior penetração nos túbulos dentinários e canais acessórios potencializando o efeito da água ozonizada (Martins, 2018). Apesar da Ozonioterapia na Odontologia abranger várias áreas estudiosos como Silva LC (2019) acredita que, as principais áreas que utilizam ozônio como tratamento complementar são a Dentística, Periodontia e Cirurgia oral (Silva, 2019).

Na questão da administração do ozônio, Martins IVR (2018), afirma que se administrado em concentrações adequadas, com tempo de exposição ideal e se aplicado de forma correta a terapia é eficaz, porém não existe protocolos sobre a concentração ideal de utilização do ozônio (Martins, 2018). Silva LC (2019), Ferreira S et al (2013) e Noites R et al (2014) também concordam que, há poucas informações sobre a quantidade de doses, concentração e seu uso ainda não é bem definido, sendo necessário mais estudos para definir a quantidade de doses e tempo de aplicação para que a Ozonioterapia venha a ser cada dia menos traumática e efetiva nos tratamentos odontológicos (Ferreira et al, 2013; Silva, 2019). Porém Nogales CG et al (2016) deixa claro que, devido a forma comercial existem poucos dispositivos específicos para a aplicação na Odontologia, sendo necessário uma adaptação da aplicação médica para a Odontologia, de forma que seja uma técnica mais simples e que não perca a efetividade (Nogales et al, 2016).

\section{Conclusão}

Em virtude dos fatos mencionados neste artigo, conclui-se que a Ozonioterapia como coadjuvante no tratamento endodôntico é eficaz para redução de microrganismos isso devido as suas propriedades terapêuticas como ação antimicrobiana, efeito debridante, estimulador de angiogenese e cicatrizante. Devido suas diversas propriedades serem capazes de reduzir a carga microbiana do sistema de canais radiculares, a Ozonioterapia é um grande aliado no tratamento endodôntico 
convencional, podendo ser utilizado por meio de gás, água e óleos, além de poder ser utilizado as suas diversas formas juntas ou separadas. Apesar de todos os seus benefícios demonstrados neste artigo, é necessário mais estudo para que se possa definir uma técnica padrão, que deixe claro a quantidade utilizada, o tempo de administração, fazendo com que essa terapia alternativa seja cada vez mais atraumática e eficaz na odontologia e mais especificamente na endodontia.

\section{Referências}

Ajeti, N. N., Krasniqi, T. P., \& Apostolska, S. (2018). The Effect of Gaseous Ozone in Infected Root Canal. Journal of Medical Sciences. 6(2), $389-396$.

Belegote, I. S., Penedo, G. S., Silva, I. C. B., Barbosa, A. A., Belo, M. T. N., \& Izolani Neto, O. (2018). Tratamento de doença periodontal com ozônio. Braz J Surg Clin Res. 23(2), 101-4.

Cruz, H. F. O. (2006). Avaliação "in vitro" da associação do efeito antimicrobiano do ozônio a veículos e curativos de demora em diferentes períodos de tempo de armazenagem. Dissertação. Universidade estadual Paulista Júlio de Mesquita Filho, Araraquara, SP, Brasil.

Estrela, C. (2018). Metodologia Científica: Ciência, Ensino, Pesquisa. Editora Artes Médicas.

Farac, R. V. (2010). Avaliação do efeito bactericida do ozônio associado ao Propilenoglicol em canais radiculares contaminados com Enterococcus faecalis em diferentes períodos de tempo de armazenagem. Dissertação. Faculdade de Araraquara, Araraquara, SP, Brasil.

Ferreira, M. B. (2011). Efeito na reparação óssea periapical da ozonioterapia como coadjuvante ao tratamento endodôntico. Estudo clínico-radiográfico. TCC. Faculdade de Odontologia da Universidade de São Paulo, São Paulo, SP, Brasil.

Ferreira, S., Mariano, R. C., Garcia Júnior, I. R., \& Pellizer, E. P. (2013). Ozônioterapia no controle da infecção em cirurgia oral. Rev Odontol Araçatuba. $34(1), 36-8$

França, G. R., \& Ferreira, L. L. (2019). Ozonioterapia e sua aplicação na odontologia: revisão de literatura. TCC. Universidade Tiradentes, Aracaju, SE, Brasil.

Martins, I. V. R. (2018). Aplicação do ozônio na terapêutica do sistema de canais radiculares: revisão de literatura. TCC. Faculdade de Ciências da Saúde da Universidade de Brasília. Brasília, DF, Brasil.

Moreira, M. J. F., Reis, A. B., Dietrich Martins, L. H. B., \& Barros, D. V. (2019). Ozonioterapia- tratamento complementar ao tratamento endodôntico: revisão de literatura. Rev Odontol Contemp. 3(1), 73-80.

Morette, D. A. (2011). Principais aplicações terapêuticas da ozonioterapia. TCC. Universidade Júlio de Mesquita Filho, Botucatu, SP, Brasil.

Nesi, A. K. (2018). Ozonioterapia: o uso do ozônio na odontologia. TCC. Centro Universitário São Lucas, Porto Velho, RO, Brasil.

Nimer, H. Y. Y. (2018). Ouso da ozonioterapia nas diversas especialidades da odontologia. TCC. Universidade de Santa Cruz do Sul, Santa Cruz do Sul, RS, Brasil.

Nogales, C., \& Franscinp, A. V. (2014). Relatório técnico aplicação de ozônio na odontologia. https://www.aboz.org.br/biblioteca/relatorio-tecnico-aboz/22/

Nogales, C. G., Ferreira, M. B., Montemor, A. F., Rodrigues, M. F. A., Marques, J. L. L., \& Antoniazzi, J. H. (2016). Ozone therapy as an adjuvant for endondontic protocols: microbiological - ex vivo study and citotoxicity analyses. J Appl Oral Sci. 24(6), 607-13.

Nogales, C.G. (2011). Parâmetros da ação antimicrobiana e da citotoxicidade do ozônio para aplicação na endodontia. Dissertação. Faculdade de Odontologia da Universidade de São Paulo, São Paulo, SP, Brasil.

Noites, R., Vaz, C. P., Rocha, R., Carvalho, M. F., Gonçalves, A., \& Vaz, I. P. (2014). Synergistic Antimicrobial Action of Chlorhexidine and Ozone in Endodontic Treatment. BioMed Research International. 2014, 1-6

Oliveira, L. E. A., Queiroz, H. M. A., Feitosa, E. A., Chagas, R. B., Brígido, J. Á., \& Saldanha, A. D. D. (2018). Ozonioterapia e odontologia: Novas perspectivas. Conexão fametro 2018: Inovação e criatividade. XIV Semana acadêmica. Pp.1-7.

Paez, T. T., Pereira, P. A. I., Assis, L., Santos, L., \& Tim, C. R. (2020). Ozonioterapia e seus aspectos controvertidos: eficácia x regulamentação jurídica específica. Rev braz cubas. 9(5), 1-21.

Rolim, G. C. (2018). Efeitos da ozonioterapia em bolsas periodontais: um ensaio clinico em boca dividida. TCC. Faculdade de Ciências da Saúde da Universidade de Brasília, Brasília, DF, Brasil.

Santos, A. C. S. V. (2018). Ozonioterapia como terapia adjunta à raspagem no tratamento periodontal de pacientes com Diabetes mellitus- série de casos. TCC. Faculdade de Ciências da Saúde da Universidade de Brasília, Brasília, DF, Brasil.

Saraiva, L., Tortelli, S. A. C., Jorge, M. S. G., Siqueira, M. O., WIbelinger, L. M., \& Miyagaki, D. C. (2019). Tratamento de disfunção temporomandibular com ozonioterapia: revisão sistemática. Rev fac odontol. 24(2), 316-21.

Silva, L. C. (2019). Uso da ozonioterapia na odontologia: revisão de literatura integrativa. Monografia. Faculdade Maria Milza, Governador Mangabeira, BA, Brasil.

Silva, N. L. S., \& Drummond, V. P. A. (2019). Ozonioterapia na odontologia: revisão de literatura. TCC. Universidade de Uberaba, Uberaba, MG, Brasil. 